\section{Surfing for Social Integration: Mental Health and Well-Being promotion through Surf Ther- apy among Institutionalized Young People}

\author{
Margarida Gaspar de Matos ${ }^{1,2,3 *}$, Anabela Santos ${ }^{1}$, Cristiana \\ Fauvelet $^{1}$, Francisco Marta ${ }^{4}$, Ema Shaw Evangelista ${ }^{4}$, José \\ Ferreira $^{4}$, Miguel Moita ${ }^{4}$, Tim Conibear ${ }^{5}$ and Matt Mattila ${ }^{5}$ \\ ${ }^{1}$ Aventura Social, University of Lisbon, Lisbon, Portugal \\ ${ }^{2}$ William James Research Centre/ISPA, Lisbon, Portugal \\ 3/SAMB/Lisbon University, Lisbon, Portugal \\ ${ }^{4}$ Portuguese Association of Pedagogy and Mental Health, Lisbon, Portugal \\ ${ }^{5}$ Waves for Change, Cape Town, South Africa
}

\section{Introduction}

In 2015, there were 8600 children and adolescents in residential care in Portugal, of whom 4880 were between 10 and 17 years of age [1]. Oriol, Sala-Roca, \& Filella [2] warn that adolescents in such care are more likely to have difficulties in social development and emotional skills. Studies show that institutionalized children have a higher prevalence of behavioral problems and deficits in adaptive functioning compared to children in the general population and the question often raised is the kind of developmental and social opportunities that they may face $[3,4]$. The national institute for social security [1] highlights the importance of interventions that contemplate the development of affective and social competencies, the development of programs adapted to the capacities and needs of these children and young people [1].

In this regard, Surf-Salva Camp 2016 was a pioneering Portuguese project undertaken during the summer of 2016, which aimed to contribute to the promotion of wellbeing and mental health, social inclusion, as well as developing beach security values and social citizenship through lifesaving and first-aid skills training in children and youth in foster care institutions. Surf can be used as a therapeutic mediator, and an increasing body of studies worldwide validate its use among vulnerable populations [5-7].

As examples of this practice, we highlight, in Australia, the "one wave" project (http://onewaveisallittakes.com) and the "waves for change" project in South Africa (http://www.waves-for-change. org), both working to promote mental health and wellbeing through surf, the latter was conceived to work with vulnerable and homeless youth, exposed to violence and traumatic experiences. With regard to the "waves for change" project, which had a major influence on the Surf-Salva Camp 2016 project, Snelling [8] proposes the term Surf Therapy to designate the benefits of the practice of surfing together with psycho educational activities when working with children and adolescents at risk of social exclusion, as an alternative means to increase psychosocial wellbeing and to reduce the risk of social exclusion.

The "waves for change" was the inspiration for Surf Salva Camp 2016, when the Portuguese professional surfer José Ferreira met the project in one of the times he was at Cape Town. Inspired and supported by "waves for change", the Surf Salva Camp 2016 had its target defined, adapting it to local needs (vulnerable youth in foster care homes), but sharing the main premise: to work with vulnerable youth who have been exposed to violence and/or traumatic events with positivity and hope through a conjoint of surfing and social emotional learning $[8,9]$. This project besides surf training and social competence skills, also promotes beach safety through lifesaving certificates and first aid training [9].

In Europe, more specifically in the United Kingdom, there exists "the wave project" (https://www.waveproject.co.uk), whose authors report seven factors that interact and motivate a change among the individuals of the target population, who were young people facing mental health problems and social exclusion: 1) the sea provides a 
restorative environment; 2) individuals feel a connection with nature when they are in or by the sea; 3 ) surfing guarantees a sensory experience that assists in learning and promotes resilience; 4) a culture of acceptance allows young people to feel included; 5) recognition and positive reinforcement help in the development of a positive self-concept and self-esteem; 6) the existence of people with reference models proved to be beneficial; 7) regular contact between the participants and the instructors led to the building of trust and fostered learning [6].

Other projects exist that use the same paradigm of surf therapy with other populations, appearing in literatures sometime with other designations as "ocean therapy" [10], "surf medicine" [11] or "intervention through surfing" [12]. On one hand, there are projects focussing on children and youth with developmental disorders and/ or other disabilities, which sometimes are under the umbrella of "adapted surf". These projects assessment validated surf therapy as a way to decrease internalised symptoms and increase self-confidence, self-esteem, social skills, motivation about physical activity, $[5,12,13]$ self-control, cooperation, responsibility, involvement [14] and social inclusion [12]. On the other hand, there are projects working through surf with addiction disorders, with war veterans with posttraumatic stress disorder, depression [10] and combat-related poly-trauma [11], validating surf therapy as a relevant form of holistic treatment.

Based on the projects mentioned above, the main objective of Surf-Salva Camp 2016 was the implementation of a surf camp for vulnerable adolescents with psychosocial risk, where group dynamics, lifesaving and first aid skills training were added as part of the surfing experience. In combination with surf practice and the benefits of contact with nature within a therapeutic environment integrated by a multidisciplinary team. It was hypothesized that the 1) participants on Surf-Salva Camp 2016 would have decreased values on behavioural problems and 2) the majority of the participants would feel that had learned surfing skills, self-regulation strategies, social and emotional skills and feel part of the group.

\section{Methods}

\section{Participants}

The Surf Salva Camp 2016 project included 48 adolescents (70.8\% boys) between 10 and 16 years of age, with a mean age of 13 years $(\mathrm{SD}=1.7)$. It was a convenience sample including adolescents in a situation of vulnerability and psychosocial risk, living in institutions providing temporary or permanent residential care, with which a partnership had been established. There were four of these institutions whose young people were included in three Surf Salva Camps.

\section{Procedure}

The Surf-Salva Camp 2016 took place on Carcavelos beach (Cascais) between June $21^{\text {st }}$ and September $8^{\text {th }} 2016$, with 3 camps at different dates. In each Camp, 8 morning sessions were held twice a week each with duration of 4 hours, before the Camps began, individual meetings were held between the care institutions and the association responsible for the project, which included the formal presentation of the project, a description of the objectives, mission, and values.

The sessions included 1) activities to promote social and emotional skills, 2) group cohesion activities, 3) surfing training, 4) awareness actions for an active safety culture at the beach along with training with lifesaving and first aid skills and 6) group reflection activities.
The multidisciplinary team were constituted by the camp coordinator (a psychologist), two specialized technicians (psychology and sociology areas), and three surf instructors. Additionally, there were two training agents for the lifesaving and first aid skills training from Instituto de Socorro a Náufragos (for more detailed information see Matos, Santos, Fauvelet, \& Aventura Social [15]).

The surf camp program, designed by the multidisciplinary team, combined the practice of surfing, social emotional learning and the contact with water, to create a mental health and wellbeing setting based on logic of respect, care, learning and relationships builder. Surf therapy as a new alternative therapy was meant possible by the following factors:

1. A multidisciplinary team, combining psychologists and surf instructors

2. Planning and presenting a structure session that offers security, but at the same time allows each individual to express him/herself according to his/her needs and/or possibilities in each session, practicing an attitude of respect for the self and freedom of choice

3. The relationship technician-youth made possible because of the adequate ratio adults-adolescents

4. The social integration factor that allowed the adolescents to experience their peer-relationship difficulties but also to overcome them

5. The characteristics of a privileged relaxing setting as the water is, but also all the details that beach has within like sound, olfactory and sensorial information

6. The learning of social and emotional competencies alongside with a challenging physical activity like surf is, which is healthy lifestyle promoter and very rewarding in terms of self-esteem and self-efficacy, that can be transformed in internal strengths

7. The reflection activities that allowed the youth to make cognitive restructuring process when trying to think and solve problems in alternative ways

\section{Instruments}

At the beginning and at the end of each camp an evaluation of the impact of the Surf-Salva Camp 2016 was carried out concerning the areas considered relevant and/or at risk for the target. The initial assessment consisted of the Strengths and Difficulties Questionnaire (SDQ) $[16,17]$ applied to young people and their tutor or legal guardian. SDQ is a measure that seeks to assess emotional characteristics and externalizing behaviors [16]. It consists of 25 items divided equally by 5 subscales: pro-social behavior, hyperactivity, emotional problems, behavior, and relationship [16]. The answers to each item are given on a basis of a 3-point scale (1-not true until 3-certainly true), corresponding high scores to more emotional and behavioral difficulties [16]. This questionnaire refers to the events of the last six months, although for this study it was used as a time reference last week.

In the final assessment, besides SDQ, we used the youth experiences survey (Hansen \& Larson, 2002 translated and adapted by Matos et al., 2015 and adapted to this work by Matos, Santos, Fauvelet, and Social Adventure [18-20]). The completion of the scales took place during the time of the session, in order to ensure that the adolescents had help in understanding the questions, if necessary.

\section{Data analysis}

A first analysis included 29 of the initial 48 youngsters, 17 of whom were male $(58.6 \%)$ and by means of raw descriptive data (\%), 
Citation: Matos MG, Santos A, Fauvelet C, Marta F, Evangelista ES, et al. (2017) Surfing for Social Integration: Mental Health and Well-Being promotion through Surf Therapy among Institutionalized Young People. J Community Med Public Health Care 4: 026.

- Page 3 of 6 •

Youth Experiences Survey at Surf-Salva Camp 2016

\begin{tabular}{|c|c|}
\hline \multicolumn{2}{|c|}{ Youth } \\
\hline Yes & No \\
\hline $\mathrm{F}$ & $\mathrm{F}$ \\
\hline (\%) & (\%) \\
\hline
\end{tabular}

Exploration

\begin{tabular}{|c|c|}
\hline \multicolumn{2}{|l|}{ Exploration } \\
\hline Tried doing new things & 28 \\
\hline Tried a new way of acting & 22 \\
\hline Did things that he/she does not do anywhere else & 24 \\
\hline Identity &
\end{tabular}

$28(96.6)$

$22(75.9)$

$1(3.4)$

$24(82.8)$

$\begin{array}{r}1(3.4) \\ 7(24.1) \\ \hline 5(17.2)\end{array}$

\begin{tabular}{|l|l|l|l}
\hline & \\
\hline & & \\
\hline
\end{tabular}

\begin{tabular}{l}
\multicolumn{2}{|c|}{ Institutional Tutors } \\
\begin{tabular}{|c|c} 
Yes & No \\
\hline F & F \\
\hline$(\%)$ & $(\%)$ \\
\hline
\end{tabular}
\end{tabular}

(\%)

\begin{tabular}{|l|l|l|}
\hline $20(64.5)$ & $9(29.0)$ & $9(29.0)$ \\
\hline $20(64.5)$ & $5(17.2)$ & $5(17.2)$ \\
\hline $24(82.8)$ & $15(57.7)$ & \\
\hline $24(82.8)$ & $11(42.3)$ &
\end{tabular}

\section{$7(96.4)$}

\begin{tabular}{|c|c|}
\hline $1(3.6)$ \\
\hline $3(17.2)$ \\
\hline
\end{tabular}

\begin{tabular}{|c|c|}
\hline \multicolumn{2}{|c|}{ Camp Team Staff } \\
\hline Yes & No \\
\hline F & F \\
\hline$(\%)$ & $(\%)$ \\
\hline
\end{tabular}

\begin{tabular}{|l|l|}
\hline & \\
\hline $28(96.6)$ & $1(3.4)$ \\
\hline & \\
\hline
\end{tabular}

\begin{tabular}{|c|c|}
\hline Started thinking about the future & \\
\hline Started thinking about self & \\
\hline Felt that he (or she) can make a difference & \\
\hline This was a positive experience & \\
\hline Thought about ethnic or racial heritage & \\
\hline Goals & \\
\hline \multicolumn{2}{|c|}{} \\
\hline
\end{tabular}

\begin{tabular}{|c|c|}
\hline \multicolumn{1}{|c|}{ Set goals } & $23(7$ \\
\hline Learned ways to achieve goals & $26(8$ \\
\hline Learned how to consider obstacles & $22(7$ \\
\hline Learned how to include others in the plan & $16(5$ \\
\hline Effort & \multicolumn{2}{|l}{}
\end{tabular}

\begin{tabular}{|l|l|l|l|l|l|}
\hline $23(79.3)$ & $6(20.7)$ & $26(89.7)$ & $3(10.3)$ & $27(93.1)$ & $2(6.9)$ \\
\hline $26(89.7)$ & $3(10.3)$ & $26(89.7)$ & $3(10.3)$ & $28(96.6)$ & $1(3.4)$ \\
\hline $22(75.9)$ & $7(24.1)$ & $25(86.2)$ & $4(13.8)$ & $26(92.9)$ & $2(7.1)$ \\
\hline $16(55.2)$ & $13(44.8)$ & $24(82.8)$ & $5(17.2)$ & $27(93.1)$ & $2(6.9)$ \\
\hline
\end{tabular}

\begin{tabular}{|c|c|}
\hline Put all energy into this activity \\
\hline Learned to push him/herself \\
\hline Learned that hard work pays off \\
\hline Learned to focus attention \\
\hline
\end{tabular}

\begin{tabular}{|l|l|}
\hline $28(96.6)$ & \\
\hline $25(86.2)$ & \\
\hline $28(96.6)$ & \\
\hline $25(86.2)$ & \\
\hline
\end{tabular}

\begin{tabular}{|c|c|}
\hline $1(3.4)$ & \\
\hline $4(13.8)$ & \\
\hline $1(3.4)$ & \\
\hline $4(13.8)$ & \\
\hline
\end{tabular}

\begin{tabular}{|l|}
\hline $27(93.1)$ \\
\hline $27(93.1)$ \\
\hline $29(100)$ \\
\hline $26(89.7)$ \\
\hline
\end{tabular}

\begin{tabular}{|l|l|}
\hline $2(6.9)$ \\
\hline $2(6.9)$ \\
\hline $3(10.3)$ \\
\hline
\end{tabular}

\begin{tabular}{|l|l|l|}
\hline $28(96.6)$ & $1(3.4)$ \\
\hline $28(96.6)$ & $1(3.4)$ \\
\hline $27(93.1)$ & $2(6.9)$ \\
\hline $28(96.6)$ & $1(3.4)$ \\
\hline
\end{tabular}

Problem solving

\begin{tabular}{|c|c|}
\hline Observed others solving problems & \\
\hline Learned to make plans & \\
\hline Tried creative problem solving & \\
\hline
\end{tabular}

\begin{tabular}{l|l|l|}
$19(65.5)$ & $10(34.5)$ & 23 \\
$19(65.5)$ & $10(34.5)$ & 20( \\
$18(64.3)$ & $10(35.7)$ & 20( \\
\hline
\end{tabular}

\begin{tabular}{|c|c|c|c|}
\hline $23(79.3)$ & $6(20.7)$ & $23(79.3)$ & $6(20.7)$ \\
\hline $20(69.0)$ & $9(31.0)$ & $27(93.1)$ & $2(6.9)$ \\
\hline $20(74.1)$ & $7(25.9)$ & $23(79.3)$ & $6(20.7)$ \\
\hline
\end{tabular}

Time management

\begin{tabular}{|c|c|}
\hline Learned about organizing time & \\
\hline Learned about setting priorities & \\
\hline Practiced self-discipline & \\
\hline
\end{tabular}

\begin{tabular}{|l|l|l|l|l|l|}
$21(72.4)$ & $8(27.6)$ & $17(60.7)$ & $11(39.3)$ & $27(93.1)$ & $2(6.9)$ \\
\hline $22(75.9)$ & $7(24.1)$ & $18(64.3)$ & $10(35.7)$ & $27(93.1)$ & $2(6.9)$ \\
\hline $22(75.9)$ & $7(24.1)$ & $18(64.3)$ & $10(35.7)$ & $27(93.1)$ & $2(6.9)$ \\
\hline
\end{tabular}

Emotional regulation

\begin{tabular}{|c|c|}
\hline \multicolumn{2}{|l|}{ Emotional regulation } \\
\hline Self-control & 22 \\
\hline Dealt with fear and anxiety & 23 \\
\hline Handled stress & 20 \\
\hline Learned to relax & 23 \\
\hline Learned that his/her emotions affect others & 20 \\
\hline Learned when to express emotions & 20 \\
\hline
\end{tabular}

\begin{tabular}{|l|l|l|l|l|l|}
\hline $22(75.9)$ & $7(24.1)$ & $17(58.6)$ & $12(41.4)$ & $25(86.2)$ & $4(13.8)$ \\
\hline $23(79.3)$ & $6(20.7)$ & $19(65.5)$ & $10(34.5)$ & $27(93.1)$ & $2(6.9)$ \\
\hline $20(69.0)$ & $9(31.0)$ & $22(75.9)$ & $7(24.1)$ & $27(93.1)$ & $2(6.9)$ \\
\hline $23(79.3)$ & $6(20.7)$ & $22(75.9)$ & $7(24.1)$ & $25(86.2)$ & $4(13.8)$ \\
\hline $20(69.0)$ & $9(31.0)$ & $21(72.4)$ & $8(27.6)$ & $26(89.7)$ & $3(10.3)$ \\
\hline $20(69.0)$ & $9(31.0)$ & $17(58.6)$ & $12(41.4)$ & $24(82.8)$ & $5(17.2)$ \\
\hline
\end{tabular}

Stress

\begin{tabular}{|c|c|c|c|c|c|c|}
\hline Felt stress in this activity & $4(13.8)$ & $25(86.2)$ & $3(10.3)$ & $26(89.7)$ & $13(44.8)$ & $16(55.2)$ \\
\hline Felt pressure & $7(24.1)$ & $22(75.9)$ & $2(6.9)$ & $27(93.1)$ & $7(24.1)$ & $22(75.9)$ \\
\hline \multicolumn{7}{|l|}{ Negative peer interaction } \\
\hline Negative influence & $6(20.7)$ & $23(79.3)$ & $1(3.4)$ & $28(96.6)$ & $5(17.2)$ & $24(82.8)$ \\
\hline Felt bullying & $3(10.3)$ & $26(89.7)$ & $1(3.4)$ & $28(96.6)$ & $4(13.8)$ & $25(86.2)$ \\
\hline \multicolumn{7}{|l|}{ Social exclusion } \\
\hline Felt like he/she doesn't belong & $3(10.7)$ & $25(89.3)$ & $4(13.8)$ & $25(86.2)$ & & \\
\hline Felt excluded & $4(13.8)$ & $25(86.2)$ & $1(3.4)$ & $28(96.6)$ & $2(6.9)$ & $27(93.1)$ \\
\hline There were cliques in this activity & $11(40.7)$ & $16(59.3)$ & $2(7.4)$ & $25(92.6)$ & $12(41.4)$ & $17(58.6)$ \\
\hline
\end{tabular}

\begin{tabular}{|c|c|c|c|c|c|c|}
\hline \multicolumn{7}{|l|}{ Stress } \\
\hline Felt stress in this activity & $4(13.8)$ & $25(86.2)$ & $3(10.3)$ & $26(89.7)$ & $13(44.8)$ & $16(55.2)$ \\
\hline Felt pressure & $7(24.1)$ & $22(75.9)$ & $2(6.9)$ & $27(93.1)$ & $7(24.1)$ & $22(75.9)$ \\
\hline \multicolumn{7}{|l|}{ Negative peer interaction } \\
\hline Negative influence & $6(20.7)$ & $23(79.3)$ & $1(3.4)$ & $28(96.6)$ & $5(17.2)$ & $24(82.8)$ \\
\hline Felt bullying & $3(10.3)$ & $26(89.7)$ & $1(3.4)$ & $28(96.6)$ & $4(13.8)$ & $25(86.2)$ \\
\hline \multicolumn{7}{|l|}{ Social exclusion } \\
\hline Felt like he/she doesn't belong & $3(10.7)$ & $25(89.3)$ & $4(13.8)$ & $25(86.2)$ & & \\
\hline Felt excluded & $4(13.8)$ & $25(86.2)$ & $1(3.4)$ & $28(96.6)$ & $2(6.9)$ & $27(93.1)$ \\
\hline There were cliques in this activity & $11(40.7)$ & $16(59.3)$ & $2(7.4)$ & 25 (92.6) & $12(41.4)$ & $17(58.6)$ \\
\hline
\end{tabular}

25 (86.2)

Negative peer interaction 


\begin{tabular}{|c|c|c|c|c|c|c|}
\hline \multicolumn{7}{|l|}{ Technical skills } \\
\hline Purposes of warming up exercises & $25(86.2)$ & $4(13.8)$ & $26(89.7)$ & $3(10.3)$ & $23(79.3)$ & $6(20.7)$ \\
\hline Learned how to prevent injury & $24(82.8)$ & $5(17.2)$ & $22(75.9)$ & $7(24.1)$ & $27(93.1)$ & $2(6.9)$ \\
\hline Was able to get into water & $25(86.2)$ & $4(13.8)$ & $25(86.2)$ & $4(13.8)$ & $28(96.6)$ & $1(3.4)$ \\
\hline Felt good in the water & $25(89.3)$ & $3(10.7)$ & $24(82.8)$ & $5(17.2)$ & $25(86.2)$ & $4(13.8)$ \\
\hline Was able to lie on the surfboard & $27(96.4)$ & $1(3.6)$ & $25(92.6)$ & $2(7.4)$ & $25(86.2)$ & $4(13.8)$ \\
\hline Step 1 & $28(96.6)$ & $1(3.4)$ & $24(100)$ & & $27(93.1)$ & $2(6.9)$ \\
\hline Step 2 & $25(89.3)$ & $3(10.7)$ & $24(100)$ & & $22(75.9)$ & $7(24.1)$ \\
\hline Step 3 & $25(89.3)$ & $3(10.7)$ & $23(92.0)$ & $2(8.0)$ & $23(79.3)$ & $6(20.7)$ \\
\hline Line up & $24(85.7)$ & $4(14.3)$ & $23(92.0)$ & $2(8.0)$ & $6(20.7)$ & $23(79.3)$ \\
\hline Learned technical terms & $26(89.7)$ & $3(10.3)$ & & & $25(89.3)$ & $3(10.7)$ \\
\hline \multicolumn{7}{|l|}{ Safety at the Sea } \\
\hline Learned how to help others & $25(86.2)$ & $4(13.8)$ & $18(62.1)$ & $11(37.9)$ & $23(79.3)$ & $6(20.7)$ \\
\hline Learned how to be safe at the beach & $25(86.2)$ & $4(13.8)$ & $20(69.0)$ & $9(31.0)$ & $25(89.3)$ & $3(10.7)$ \\
\hline Felt satisfaction about being able to help & $26(89.7)$ & $3(10.3)$ & $24(82.8)$ & $5(17.2)$ & $27(93.1)$ & $2(6.9)$ \\
\hline \multicolumn{7}{|l|}{ Group skills (social competences) } \\
\hline To be part of the group & $24(82.8)$ & $5(17.2)$ & $28(96.6)$ & $1(3.4)$ & & \\
\hline Team work & $26(89.7)$ & $3(10.3)$ & $24(82.8)$ & $5(17.2)$ & $27(93.1)$ & $2(6.9)$ \\
\hline Help others & $26(92.9)$ & $2(7.1)$ & $23(79.3)$ & $6(20.7)$ & $20(69.0)$ & $9(31.0)$ \\
\hline Shared responsibilities & $24(82.8)$ & $5(17.2)$ & $22(75.9)$ & $7(24.1)$ & $22(75.9)$ & $7(24.1)$ \\
\hline Was patient with friends & $27(93.1)$ & $2(6.9)$ & $22(75.9)$ & $7(24.1)$ & $25(86.2)$ & $4(13.8)$ \\
\hline Manage others influence & $22(75.9)$ & $7(24.1)$ & $22(75.9)$ & $7(24.1)$ & $22(75.9)$ & $7(24.1)$ \\
\hline \multicolumn{7}{|l|}{ Interpersonal relationships } \\
\hline Made friendships & $22(78.6)$ & $6(21.4)$ & $24(82.8)$ & $5(17.2)$ & $20(69.0)$ & $9(31.0)$ \\
\hline Have something in common with someone & $26(89.7)$ & $3(10.3)$ & $22(75.9)$ & $7(24.1)$ & & \\
\hline \multicolumn{7}{|l|}{ Relations with important adults } \\
\hline Had good relationships with adults & $24(82.8)$ & $5(17.2)$ & $15(51.7)$ & $14(48.3)$ & & \\
\hline Had good talks with adults & $19(65.5)$ & $10(34.5)$ & $19(65.5)$ & $10(34.5)$ & & \\
\hline \multicolumn{7}{|l|}{ Future expectations } \\
\hline Thought about the future & $20(69.0)$ & $9(31.0)$ & $12(41.4)$ & $17(58.6)$ & $25(89.3)$ & $3(10.7)$ \\
\hline Wants to continue surfing & $24(82.8)$ & $5(17.2)$ & $26(89.7)$ & $3(10.3)$ & & \\
\hline
\end{tabular}

Table 1: Questionnaire youth experiences survey at Surf-Salva Camp 2016, from youth, institutional Tutors and camp team staff (Hansen \& Larson, 2002, translated and adapted by Matos et al., 2015 and adapted to this work by Matos, Santos, Fauvelet\& Social Adventure [18-20]).

analysis was made of the perceptions of young people and staff about the way Surf-Salva Camp 2016 affected their lives and behaviours. This analysis included those who were able to complete a final evaluation (post-evaluation), paired with their tutors and Surf Staff.

A second analysis included 32 adolescents from the initial 48 youngsters. 20 of whom were male (62.5\%). This analysis included those who were able to complete both the initial assessment (pre-evaluation) and the final evaluation (post-evaluation). Analyses included basic descriptive analyses and comparative analysis (paired $t$ tests).

\section{Results}

Regarding the first analysis-youth experiences survey at Surf-Salva Camp 2016, there was a positive increase regarding the subscales effort and perseverance, problem-solving, time management, social competences and interpersonal relationships, suggesting that the youngsters felt that the project brought changes with regard to these dimensions. Emotional adjustment items also increased, suggesting that youngsters perceived that the surfing had helped them. As to the scale of negative situations, most of the youngsters reported not having felt either stress, the negative influence of peers or social exclusion.
Regarding the prospects for the future: "this activity made him/her want to continue surfing", $83 \%$ of young people answered affirmatively (Table 1).

These results also strongly suggest that the competences related to learning surfing (items 38-47) and learning safety at sea (items 48-50) were reported as a positive achievement for most of the youngsters. Youngsters' perceptions were corroborated by staff of the camp and tutors from the institutions and a majority of inter-judge reliability was highlighted grey.

According to the results of the second analysis (Table 2), there was an improvement in the difficulties perceived by the youngsters, and these were corroborated by the staff of the Camp and the tutors of the institutions. What is more, for overall skills, positive effects were verified. However, the latter was only true with regard to self-perception. The t-test of paired samples was performed to evaluate the impact of the Surf-Salva Camp 2016 on the subscales of the Capacities and Difficulties Questionnaire (SDQ-PT), using both the self-report versions and by the parents (tutors) versions. Considering the self-report, there is a statistically significant decrease in the subscale behaviour 


\begin{tabular}{|c|c|c|c|c|c|c|c|c|}
\hline \multirow{2}{*}{ Subscales SDQ-PT } & \multicolumn{4}{|c|}{ Self-Perceptions } & \multicolumn{4}{|c|}{ Tutors } \\
\hline & Initial (X) & Final $(X)$ & $\mathbf{t}$ & $\mathbf{p}$ & Initial (X) & Final $(X)$ & $\mathbf{t}$ & $\mathbf{p}$ \\
\hline Emotional problems & 8.64 & 8.54 & 0.27 & & 8.61 & 7.65 & 2.6 & 0.05 \\
\hline Behavioural problems & 7.47 & 6.63 & 2.39 & 0.05 & 7.77 & 6.84 & 2.1 & 0.05 \\
\hline Hyperactivity & 8.62 & 8.2 & 0.97 & & 8.74 & 8.42 & 0.69 & \\
\hline Peer problems & 7.86 & 7.32 & 1.68 & & 7.86 & 7.24 & 1.9 & \\
\hline
\end{tabular}

Table 2: Results of the SDQ-PT [16], preand post-evaluation: self-perception and institutional tutors.

problems between the initial evaluation $(\mathrm{M}=8.60, \mathrm{SD}=1.65)$ and the final evaluation $[\mathrm{M}=8.60, \mathrm{SD}=1.70, \mathrm{t}(29)=2.57,0.05]$.

According to the evaluation of the tutors from the institutions, there is a statistically significant decrease in the emotional symptoms subscale between the initial evaluation $(\mathrm{M}=8.63, \mathrm{SD}=2.47)$ and the final evaluation $[\mathrm{M}=7.63, \mathrm{SD}=1.50, \mathrm{t}(29)=2.61, \mathrm{p}<0.05]$, a statistically significant decrease in subscale behavioural problems, between the initial evaluation $(\mathrm{M}=8.47, \mathrm{SD}=2.08)$ and the final evaluation $[\mathrm{M}=7.60, \mathrm{SD}=1.59, \mathrm{t}(29)=2.62, \mathrm{p}<0.05]$ and also a statistically significant decrease in the total scale of difficulties between the initial evaluation $(M=37.11, S D=5.79)$ and the final evaluation $[M=34.46$, $\mathrm{SD}=3.61, \mathrm{t}(27)=2.67, \mathrm{p}<0.05]$.

\section{Discussion}

Surf-Salva Camp 2016 was an innovative project in Portugal, since until now there was not a program working with institutionalized youth through surf therapy. Our aim was to understand the impact of the program on a group of adolescents between 10 and 17 years old, living in foster care homes. It was hypothesized that the 1) participants in Surf Salva Camp 2016 would have decreased values on behavioural problems and 2) the majority of the participants would feel that had learned surfing skills, self-regulation strategies, social and emotional skills and would feel part of the group. The stated hypothesis were in line with the literature, namely results on self-management, empathy and improved behaviour, wellbeing, social interactions and engagement among youth [6].

The Surf-Salva Camp 2016 project design followed previous similar projects, namely "waves for change", in South Africa and "the wave project", in the United Kingdom. Like the above-mentioned programs, Surf-Salva Camp 2016 aimed to promote health and well-being in vulnerable youth. According to research in the field, these adolescents present a higher prevalence of difficulties in social, cognitive, affective and emotional development, as well as behavioural problems [2-4,21].

One of the dimensions that the Surf Salva Camp 2016replicated was the integration in the community as the waves for change program does, which includes visits to the homes of supported children and youth $[8,9]$. The Surf Salva Camp 2016 project interacted with the directors and referral educators of the adolescents, as a result there was a growing interest in the program, as well as subsequent contacts in the search for continuity and support in fundraising tasks.

Snelling [8] states that surf can be used as a therapeutic tool with children and adolescents at risk of social exclusion and names this procedure Surf-therapy, aiming at reducing social psychological symptoms and increasing psychosocial well-being through Surf. The Surf-Salva Camp 2016 was implemented in three camps each one with 16 participants. The sessions combined the practice of surf together with psycho educational activities that aimed to promoted social and emotional competencies and group cohesion.
With regard to the first analysis, the results showed positive outcomes as other similar projects shows [5,6,12-14]. Regarding the items related to emotional regulation, most of the participants felt improvements and reported that they did learn about social and emotional competences, what can be a consequence of the fact that surf training was learn alongside with social emotional competencies. Group integration had also a positive result with $89.3 \%$ of the participants indicating that they felt included. As others similar programs have the same outcome [6,14], one can think about the importance of group activities, but also the importance of the individual respect climate that was promoted though the camp. They also reported not having felt stress and having succeeded in establishing positive relationships with significant adults. These data are in agreement with Godfrey, et al. [6], who states that the sea provides a refreshing environment, that subjects feel in connection with nature when they are in the sea and this experience promotes resilience, a sense of inclusion, development of self-concept and self-esteem, and contact that with the other participants and coaches facilitates building trust and promotes learning. Regarding the second analysis, which was related to the impact of surfing on maladaptive behaviours, such as hyperactivity, emotional, behavioural and peer problems, positive results were also found. The project "the wave" which works specifically with mental health issues, states that surf therapy is a "valuable and cost-effective way to deliver mental health care" [6]. This study also validates surf therapy in reducing problem behaviors once there was a statistically significant decrease in the subscale behaviour problems, in both the self-report version and the institutions' technicians report. According to the tutors' perception, there was also a decrease in the subscale of emotional symptoms and in the scale referring to total difficulties. The fact that adolescents completed the instrument scales on the last camp session, an especially emotional day, where some youngsters were more fragile, some having cried, showing sadness because of the end of the camps and worried about the not knowing if they would be with those people again or if they would integrate new surf camps could be influenced the answer to items like "I'm often unhappy", "I worry a lot" or "I have many fears". In future surf camps it is thought that an alternative possibility will be the completion of the questionnaires the day after the end of the camp or at the end of the penultimate session.

There were a number of difficulties during the implementation and evaluation of this process that must be overcome in future Camps as for instance the difficulties of interaction with the care Institutions, the fact that the evaluation team was not present from the very beginning of the project design, and also the difficulties in having the evaluations completed by both the participants and their tutors. Nevertheless, the positive impact of Surf Therapy was evident at the Surf-Salva Camp 2016, where $83 \%$ of young people, who were not always very easy to motivate and who found it difficult at times to comply with extra activities as reported by their tutors, responded that they want to continue practicing Surf. 


\section{Conclusion}

According to the evaluation carried out, the intervention had a positive impact among the youth who took part. The areas of self-knowledge, exploration, effort and perseverance, problem-solving, time management, group competencies, interpersonal relationships and emotional regulation, all developed positively throughout the project. As for the future perspectives, the great majority expressed great interest in continuing to surf. The analysis of the SDQ-PT questionnaires suggests a significant decrease in the variable behaviour problems between the two assessment moments, a result corroborated by the institutions' technicians. In the opinion of the institutions' technicians there was also a significant decrease in the subscale emotional symptoms and globally, in total perceived difficulties.

Regarding the results obtained, it can be concluded that surfing can be used as an instrument of psychotherapeutic intervention since our results show that it seems to be beneficial for the promotion of a healthy lifestyle, wellbeing and personal and social skills in young people in contexts of psychosocial vulnerability.

Results suggest that this procedure, which Snelling [8] termed Surf Therapy, had a number of positive effects: as seen, exploration, effort and perseverance, problem-solving, time management, social competencies, interpersonal relationships and emotional regulation had a positive evolution among the participants throughout the project.

Results support the claim that within a suitable framework regarding the components about surf therapy (i.e., the importance of an adequate ratio adult-youth that can be 1:2 or 1:3; social and emotional learning; lifesaving and first aid skills training; reflection activities in group), with a constant and multidisciplinary team and with adequate supervision and evaluation (in this project made by an expert in youth mental health and wellbeing university professor)surf therapy can be a very promising alternative in the psychosocial care of youth at risk. In this regard, public policies should consider this suggestion in the development of policies related to vulnerable institutionalized young people.

Furthermore, it is thought that similar results could be obtained with risk populations in younger children and projects suggestion in the adapted surfing area $[5,12,13]$. Concerning the impact that this project had in social issues, future interventions should address surf therapy when working with families in vulnerable situations and as a prevention strategy. As the project waves for change and the wave project, this project aim to enhance social integration in a deeper concern, expanding the permanence of the surf therapy camps throughout the year and to promoting youth employment in surf activities related.

\section{Acknowledgement}

The authors would like to thank LIDL Portugal (financial and promoting sponsor) and the Instituto de Socorro a Náufragos (promoting institution) for making the Surf Salva Camp 2016 possible; the authors would also like to thank all of the staff from Pensamento Vivo, namely the ones who worked in the camps, Aventura Social, FMH/ University of Lisbon; all of the staff at waves for change; and all the young people and tutors and staff from the institutions involved: Santa Casa da Misericórdia de Cascais (Centro de AcolhimentoTemporário de Tercena), Associação Novo Futuro (Casas Amarela, Azul, Branca, Laminga, Laranja, Lilás e Verde), Casa Pia de Lisboa, Santa Casa da Misericórdia de Lisboa (Lar S. Francisco de Assis).

\section{References}

1. Casa 2015, Relatório de Caracterização Anual da Situação de Acolhimento das Crianças e Jovens (2016) Departamento de Desenvolvimento Social e Programas/ Unidade de Infância e Juventude. Instituto da Segurança Social I.P., Lisboa, Portugal.

2. Oriol X, Sala-Roca J, Filella G (2014) Emotional competences of adolescents in residential care: Analysis of emotional difficulties for intervention. Children and Youth Services Review 44: 334-340.

3. Clausen JM, Landsverk J, Ganger W Chadwick D, Litrownik A (1998) Mental Health Problems of Children in Foster Care. Journal of Child and Family Studies 7: 283-296.

4. Pecora PJ, Jensen PS, Romanelli LH, Jackson LJ, Ortiz A (2009) Mental Health Services for Children Placed in Foster Care: An Overview of Current Challenges. Child Welfare 88: 5-26.

5. Armitano C, Clapham ED, Lamont L, Audette J (2015) Benefits of Surfing for Children with Disabilities: A Pilot Study. Palaestra 29.

6. Godfrey C, Devine-Wright H, Taylor J (2015) The positive impact of structured surfing courses on the wellbeing of vulnerable young people. Community Pract 88: 26-29.

7. Stuhl A, Porter H (2015) Riding the waves: Therapeutic surfing to improve social skills training in children with autism. Therapeutic recreation journal 49: 253-256.

8. Snelling M (2015) Breaking cycles of violence, one wave at a time : a formative evaluation of the Waves for Change Surf Therapy programme. Institute for Monitoring and Evaluation, Cape Town, South Africa.

9. Rolfe $L$ (2016) Using evaluation and surfing to reduce violence in high-risk youth. In: World Urban Parks \& Institute of Environment and Recreation Management Congress, Cape Town, South Africa.

10. Rogers CM, Mallinson T, Peppers D (2014) High-intensity sports for posttraumatic stress disorder and depression: feasibility study of ocean therapy with veterans of Operation Enduring Freedom and Operation Iraqi Freedom. Am J Occup Ther 68: 395-404.

11. Fleischmann D, Michalewicz B, Stedje-Larsen E, Neff J, Murphy J, et al (2011) Surf Medicine: Surfing as a Means of Therapy for Combat-Related Polytrauma. JPO Journal of Prosthetics \& Orthotics 23: 27-29.

12. Lopes JT (2015) Adapted Surfing as a Tool to Promote Inclusion and Rising Disability Awareness in Portugal. Journalof Sport for Development 3: 4-10.

13. Clapham ED, Armitano CN, Lamont LS, Audette JG (2014) The Ocean as a Unique Therapeutic Environment: Developing a Surfing Program. Journal of Physical Education, Recreation \& Dance 85: 8-14.

14. Cavanaugh LK, Rademacher SB (2014) How a SURFing Social Skills Curriculum can Impact Children with Autism Spectrum Disorders. Journal of the International Association of Special Education 15: 27-35.

15. Matos MG, Santos AC, Fauvelet C, Marta F, Evangelista ES, et al. (2016) O Surf na promoção da saúde e bem-estar em jovens em contexto de acolhimento - Avaliação de uma intervenção. Journal of Clinical Child \& Adolescent Psychology 7: 433-448.

16. Goodman R, Meltzer H, Bailey V (1998) The strengths and difficulties questionnaire: A pilot study on the validity of the self-report version. European Child \& Adolescent Psychiatry 7: 125-130.

17. Fleitlich B, Loureiro MJ, Fonseca A, Gaspar F (2004) Questionário do SDQ, versão traduzida e adaptada para a população portuguesa.

18. Hansen DM, Larson R (2002) The Youth Experience Survey. Youth Development Research Project, Illinois, USA.

19. Matos MMNGD, Branquinho C, Cruz J, Tomé GMQ, Camacho INM, et al (2015) "Dream Teens" - autonomous adolescents, responsible and participants. Revista de Psicologia da Criança e do Adolescente 6.

20. Matos MG, Santos A, Fauvelet C, Social A (2016) Relatório SURFSALVACA MP 2016. Lisboa, Portugal.

21. Hukkanen R, Sourander A, Bergroth L, Piha J (1999) Follow-up of children and adolescents in residential care in children's homes. Nordic Journal of Psychiatry 53: 185-189. 